\title{
Spatial Distribution of Chain Stems and Chain Folding Mode in Polyethylene Lamellae as Revealed by Coupled Information of DSC, FT-IR, SANS, and WANS
}

\author{
Sono Sasaki, Kohji Tashiro, ${ }^{\dagger}$ Naomi Gose, Kouji Imanishi, \\ Masaaki IzUCHI, Masamichi KoBayashi, Masayuki ImaI,* \\ Masayoshi OHashi, ${ }^{* *}$ Yasuo YamaguchI, ${ }^{* *}$ \\ and Kenji OHOYAma** \\ Department of Macromolecular Science, Graduate School of Science, Osaka University, \\ Toyonaka, Osaka 560-0043, Japan \\ * Institute for Solid State Physics, The University of Tokyo, \\ Roppongi, Tokyo 106 0032, Japan \\ **Institute for Materials Research, Tohoku University, Sendai, Miyagi 980-8577, Japan
}

(Received March 17, 1999)

\begin{abstract}
Aggregation structure of polyethylene (PE) chains in the crystalline state as well as in the molten state was investigated by an organized combination of the small-angle neutron scattering, infrared spectra and thermal analysis. The used samples were the blends between the deuterated and hydrogeneous PE (and $n$-alkane), which were cocrystallized almost perfectly into the common lamella even when they were cooled slowly from the melt. The quantitative analysis of the small-angle neutron scattering data showed that the $\mathrm{D}$ and $\mathrm{H}$ species were homogeneously mixed in the melt and the radius of gyration of a chain was kept unchanged even when the chains were enrolled together into the crystalline lamellae. On the basis of the quantitative analysis of infrared spectra, the chain stems included in the crystalline lamella were found to be gathered together in a statistically random fashion. This structural idea could be also used reasonably to interpret the dependence of the melting point on the $\mathrm{D} / \mathrm{H}$ content. From all these data it was concluded that the chain folding in the PE lamella occurs in a statistically random reentry mode even for the PE samples crystallized slowly from the melt under the normal condition.

KEY WORDS Polyethylene/Blend/Aggregation Structure/Cocrystallization/Differential Scanning Calorimetry / Fourier-Transform Infrared Spectra / Small-Angle Neutron Scattering / Wide-Angle Neutron Scattering / Radius of Gyration
\end{abstract}

Investigation of aggregation structure of chains in the crystalline phase is important from such various points of view as to clarify the factors governing the crystallization phenomenon, to improve the physical properties of the samples by controlling the aggregation state of chains, and so on. In such a study a trace of the shape of an individual chain in the crystalline lamella as well as in the melt is indispensable and can give us quite valuable information about the chain conformational change during the crystallization process. ${ }^{1,2}$ At the same time, a clarification of the trace of single polymer chain embedded in the aggregation structure of chains is expected to give a unique and definite answer for the long controversial problem about the chain folding mode in the crystalline lamella (the switch-board or random reentry mode, the regular adjacent reentry mode, etc. ?). ${ }^{3-22}$ One of the useful methods to distinguish the individual chains from the aggregated chain groups is a utilization of the blend samples between the deuterated and hydrogeneous polymer species. The techniques of neutron scattering ${ }^{3-26}$ and vibrational spectrosco$\mathrm{py}^{27-33}$ are available effectively for these samples. This is based on the principle that the neutron scattering cross section ${ }^{10}$ and the vibrational frequency are different between the $\mathrm{D}$ and $\mathrm{H}$ species. ${ }^{27,28}$ For example, in order to investigate the structure of polyethylene (PE) single chain in the melt as well as in the crystalline state, many investigators used the blend samples between the high-density PE (HDPE) and deuterated high-density PE

${ }^{\dagger}$ To whom correspondence should be addressed.
(DHDPE) and they measured the neutron scattering and vibrational spectra. Unfortunately, however, these samples were doubted to be available reasonably or not, because of such a behavior that the $\mathrm{D}$ and $\mathrm{H}$ chain species were segregated from each other when the sample was cooled slowly from the melt. ${ }^{3-6,20,34}$ Because of this problem of phase segregation between the $\mathrm{D}$ and $\mathrm{H}$ species, many people avoided to use the samples crystallized by slow cooling from the melt, but rather they obtained the samples by quenching from the melt. The thus obtained sample cannot be assumed as a suitable model for the study of the aggregation state of chains, because the quenching is a special process of the sample preparation, as already pointed out by Keller. ${ }^{35}$ In order to trace the conformational change of PE chains in more normal crystalline state, we have to use the samples which are obtained by slow cooling from the melt or under the isothermal crystallization condition, i.e., the samples which do not show any phase segregation between the $\mathrm{D}$ and $\mathrm{H}$ species.

In a series of papers, ${ }^{36-44}$ we have found out the PE blend samples which could show almost perfect cocrystallization phenomenon between the deuterated (D) and hydrogeneous $(\mathrm{H})$ species even when they were cooled slowly from the melt $\left(0.3-1^{\circ} \mathrm{C} \mathrm{min}^{-1}\right)$. This cocrystallization phenomenon could be observed also in case of the isothermal crystallization from the melt even at the very small degree of supercooling $\left(0.3-0.1^{\circ} \mathrm{C}\right)$. This cocrystallizable sample was the blend between DHDPE and the hydrogeneous linear low-density PE (LLDPE) with various degrees of ethyl branchings. In 
particular the blend of DHDPE with LLDPE of $c a .17$ ethyl branching [LLDPE(2) in ref 36-44] showed almost perfect cocrystallization phenomenon. It should be noticed that the $\mathrm{D}$ and $\mathrm{H}$ blends of the high-density PEs without side branchings does not show such a perfect cocrystallization phenomenon but a phase segregation of these two species when crystallized at such a low cooling rate. We investigated the crystallization behaviors of the DHDPE/LLDPE blends by means of wideangle and small-angle X-ray scatterings (using a synchrotron radiation), infrared spectra, DSC, light scattering, and neutron scatterings. The $\mathrm{D} / \mathrm{H}$ blend samples mentioned in ref $36-44$ and here seem to be one of the best candidates for the investigation of the aggregation structure of chains in the crystalline state attained under the normal crystallization condition. This can be said because the behavior of each chain component in the blend samples between the linear PE and branched $\mathrm{PE}$ was difficult to trace since the components of the blends have the same chemical elements $\mathrm{C}$ and $\mathrm{H}^{45-49}$ Of course it must be checked that the DHDPE/LLDPE blend sample mentioned above is not special but it shows essentially the same crystallization behavior with that observed for the typical HDPE sample. ${ }^{36-44}$

In a previous paper ${ }^{44}$ we investigated semi-quantitatively the relation between the chain aggregation in the melt and that in the crystalline state by measuring the small-angle neutron scattering (SANS) and the infrared spectra for this blend sample. After that, however, we repeated the SANS measurements several times and found some unreasonable points in the SANS data reported in that paper, which resulted in an overestimation of the temperature dependence of the radius of gyration $\left(R_{\mathrm{g}}\right)$ of a chain in the melt. (We speculated the reason for this curious temperature dependence of $R_{\mathrm{g}}$ might come from the abnormal change in the scattered neutron intensity due to the some trouble in the sample cell: probably the melted sample flowed in the heated cell and the effective volume of the sample, into which the neutron beam was incident, changed during the SANS measurement in the cooling process.) Therefore, in the present paper, we wish to report again the thus repeatedly measured SANS data and also thoroughly checked the information about the chain aggregation in the blend sample. Additionally we measured the temperature dependence of the wide-angle neutron scattering (WANS) for this sample. We also analyzed quantitatively the DSC and FT-IR data which were collected for a series of $\mathrm{PE}$ blends as well as for the $n$-alkane blends with different $\mathrm{D} / \mathrm{H}$ contents. All these experimental data, i.e., the data of SANS, WANS, FT-IR, and DSC were combined together in an organized manner, from which the aggregation structure of PE chains in the crystalline lamella as well as in the melt could be discussed more precisely and in more details. In particular it may be emphasized here that the chain folding mode, which had been a long controversial problem in polymer science, could be deduced logically and reasonably, at least for the DHDPE/LLDPE blend sample, by interpreting all the experimental data presented in this study systematically.
Table I. Polyethylene samples used in this study

\begin{tabular}{cccc}
\hline Samples & $M_{w}$ & $M_{n}$ & Ethyl branching/1000C \\
\hline DHDPE & $107 \mathrm{k}$ & $34 \mathrm{k}$ & $2-3$ \\
LLDPE & $75 \mathrm{k}$ & $37 \mathrm{k}$ & 17 \\
\hline
\end{tabular}

\section{EXPERIMENTAL}

\section{Samples}

In this study we used the samples listed in Table I. The DHDPE sample was newly purchased from Merck Chemical Co., Ltd., which was different from that used in ref 36-44. The LLDPE, which was synthesized by Metallocene catalyst, was supplied from Exxon Chemical Co., Ltd. and identical to that used in ref $36-44$ (LLDPE(2)). The content of the LLDPE component in the blends between the DHDPE and LLDPE was 0, 25, $50,75,97,99$, and $100 \mathrm{wt} \%$. These two samples were dissolved into boiling $p$-xylene at high temperature and then quenched into methanol to prepare the molecularlymixed blend samples. The thus precipitated samples were dried in vacuo at $170^{\circ} \mathrm{C}$ and cooled slowly to the room temperature at $\mathrm{ca} .1^{\circ} \mathrm{C} \mathrm{min}^{-1}$.

The blends of $n$-alkane between the $\mathrm{D}$ and $\mathrm{H}$ species were also used. The fully deuterated $n-\mathrm{C}_{30} \mathrm{D}_{62}$ sample was mixed with the normal $n-\mathrm{C}_{30} \mathrm{H}_{62}$ sample into petroleum ether solution and was precipitated into methanol to get the blend samples.

\section{Measurements}

The thermal analyses were made for these blend samples by utilizing a SEIKO SSC/5200 differential scanning calorimetry at the heating rate of $1-10^{\circ} \mathrm{C} \mathrm{min}^{-1}$.

Infrared spectra of the blends were measured at room temperature by using a Japan Spectroscopic Company FT-IR8300 Spectrometer at $2 \mathrm{~cm}^{-1}$ resolution power.

The X-ray patterns were measured at room temperature by using a Rigaku RAD-ROC X-ray diffractometer with a graphite-monochromatized $\mathrm{Cu}-K_{\alpha}$ line.

SANS measurements were performed by using the SANS-U of the Institute for Solid State Physics, the University of Tokyo, installed in the JRR-3M reactor of Tokai Research Establishment, Japan Atomic Energy Research Institute, Tokai, Ibaraki, Japan. The wavelength of incident beam was $7.0 \AA$. The sample-todetector distance was $4 \mathrm{~m}$ and the scattering signals were detected with a 2-dimensional position sensitive detector. The available $q$ range was $0.008 \AA^{-1}<q<0.08 \AA^{-1}$, where $q=4 \pi \sin \theta / \lambda$ and $\theta$ is a scattering angle. The disk-like sample was sandwiched in a pair of quartz with a rubber spacer and set into the heating cell, which was then installed into the sample chamber under a high vacuum. The sample temperature was monitored with a platinum resistance sensor. SANS was measured stepwise in the cooling process from the melt $\left(c a .172^{\circ} \mathrm{C}\right)$ to $c a$. $120^{\circ} \mathrm{C}$ and also at room temperature. All the scattering intensities were circularly averaged to give the scattering patterns as a function of $q$. The net scattering intensity of the sample, $I_{\text {sample }}$, was obtained by subtracting the scattering of the empty cell $\left(I_{\text {cell }}\right)$ from the observed scattering $\left(I_{\text {obs }}\right)$ after correction for the transmission $(\% \mathrm{~T})$. The conversion to the absolute scattering cross 
section $(\mathrm{d} \Sigma / \mathrm{d} \Omega)_{\text {total }}$ was carried out by using a data of lupolen LDPE as a standard material. The coherent cross section $(\mathrm{d} \Sigma / \mathrm{d} \Omega)_{\text {coh }}$ was obtained by subtracting the incoherent contribution of the $\mathrm{H}$ species. The structure factor $S(q)$ was calculated as $S(q)=(\mathrm{d} \Sigma / \mathrm{d} \Omega)_{\text {coh }} /$ $\left[v^{-2}\left(b_{\mathrm{H}}-b_{\mathrm{D}}\right)^{2}\right]$ where the $b_{\mathrm{H}}$ and $b_{\mathrm{D}}$ were the scattering lengths of the $\mathrm{H}$ and $\mathrm{D}$ atoms, -0.166 and $3.998 \times 10^{-12} \mathrm{~cm}$, respectively. The $v$ is the volume per one monomer.

WANS measurements were performed by using the triple-axis neutron diffractometer HERMES equipped with multichannel detectors, which belongs to the Institute for Material Research, Tohoku University, and is installed in the JRR-3M reactor of Tokai Research Establishment, Japan Atomic Energy Research Institute, Tokai, Ibaraki, Japan. The wavelength of incident beam was $1.817 \AA$. The disk sample was surrounded by a silicone rubber spacer and sandwiched by a pair of aluminum plates and then set to the sample holder tightly. This sample holder was set into the heating cell. The spectra were corrected for the scattering from the empty cell and air.

\section{RESULTS AND DISCUSSION}

\section{Interpretation of Experimental Data}

(A) Thermal Behavior of PE and Alkane Blends

The melting point $(\mathrm{mp})$ was evaluated, as conventionally, at the standing-up point of the endothermic peak of the DSC thermogram and so is a little different from the previously reported value (peak position). ${ }^{36}$ Figure 1(a) shows the mp's of a series of $n$-alkane blend between the $\mathrm{D}$ and $\mathrm{H}$ species. ${ }^{33.50}$ The mp changes almost linearly with the fraction of the $\mathrm{H}$ species. Figure $1(b)$ is the case of PE blends between DHDPE and LLDPE. Since the $m p$ of the DHDPE is higher than that of the LLDPE in this case, the slope is inversed from the case of $n$ alkane blends showing lower mp for the $\mathrm{D}$ species. The $\mathrm{mp}$ changes also continuously as in the case of $n$-alkane blends. Judging from the continuous changes of the melting behaviors, we may say clearly the almost perfect miscibility between the $\mathrm{D}$ and $\mathrm{H}$ species for these two cases of PE and $n$-alkane.

If we assume a random distribution of the $\mathrm{D}$ and $\mathrm{H}$ chain stems in both the crystalline and the molten states of the blend, then the changes of enthalpy $(\Delta H)$ and entropy $(\Delta S)$ at the melting point may be expressed approximately by the following equations. It should be noticed that the mixing enthalpy and mixing entropy, which are frequently introduced in the discussion of the thermal behavior of blends, ${ }^{51}$ are not needed to consider here because the statistically random mixing is already assumed to occur for both the crystal and the melt. Because the probabilities to make the pairs between $\mathrm{H}-\mathrm{H}$, D-D or H-D are, respectively, represented by $X^{2}$, $(1-X)^{2}$, or $2 X(1-X)$ for the molar fraction of the $\mathrm{H}$ species $X$. Then we have

$$
\begin{gathered}
\Delta H=X^{2} \Delta H_{\mathrm{hh}}+(1-X)^{2} \Delta H_{\mathrm{dd}}+2 X(1-X) \Delta H_{\mathrm{hd}} \\
\Delta S=X^{2} \Delta S_{\mathrm{hh}}+(1-X)^{2} \Delta S_{\mathrm{dd}}+2 X(1-X) \Delta S_{\mathrm{hd}}
\end{gathered}
$$

where $\Delta H_{\mathrm{hh}}, \Delta H_{\mathrm{dd}}$, or $\Delta H_{\mathrm{hd}}$ denote the enthalpy changes related to the systems constructed by only the pairs of
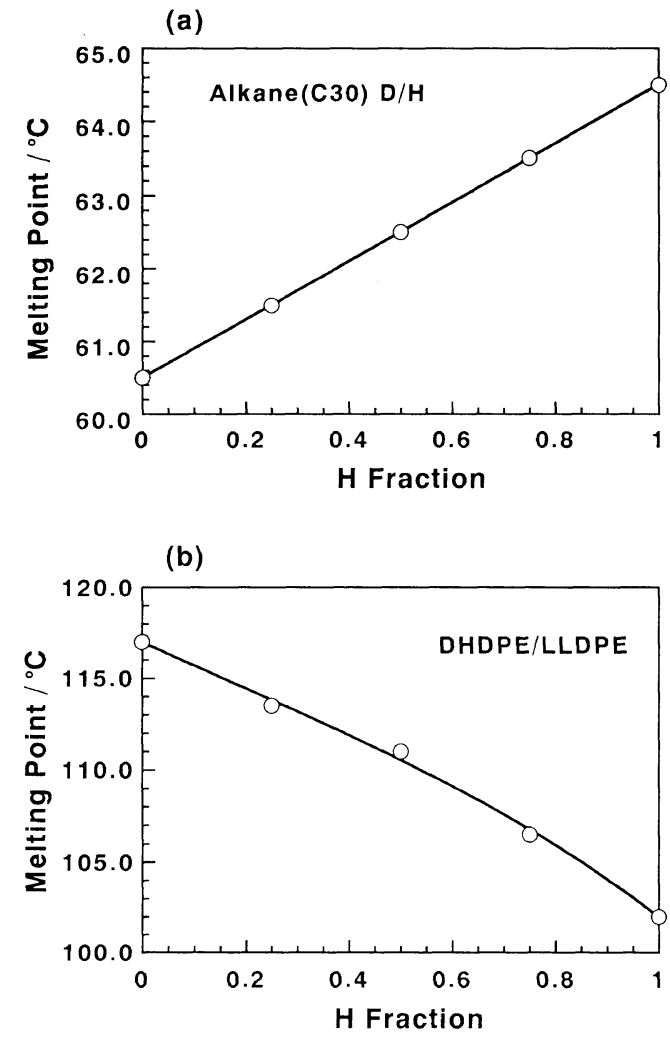

Figure 1. Dependence of melting point on the $\mathrm{H}$ species fraction in the blend samples between (a) $n-\mathrm{C}_{30} \mathrm{H}_{62}$ and $n-\mathrm{C}_{30} \mathrm{D}_{62}$ and (b) DHDPE and LLDPE. The solid lines indicate the theoretical curves obtained under the assumption of random distribution of the $D$ and $H$ species in the crystal lattice (see the text).

$\mathrm{H}-\mathrm{H}$, D-D, or $\mathrm{H}-\mathrm{D}$, respectively. It should be noted here that the entropy changes $\Delta S_{\mathrm{hh}}, \Delta S_{\mathrm{dh}}$, and $\Delta S_{\mathrm{dd}}$ include the terms coming from the thermal expansion, conformational change, the change in the $\mathrm{D} / \mathrm{H}$ mixing state, etc. Since the relations $\Delta S_{\mathrm{hh}}=\Delta H_{\mathrm{hh}} / T_{\mathrm{mhh}}^{\mathrm{o}}$ and $\Delta S_{\mathrm{dd}}=\Delta H_{\mathrm{dd}} / T_{\mathrm{mdd}}^{\mathrm{o}}$ are applicable, where $T_{\mathrm{mhh}}^{\mathrm{o}}$ and $T_{\mathrm{mdd}}^{\mathrm{o}}$ are the melting temperatures for the pure $H$ and $D$ species, respectively, then the melting temperature of the randomly mixed $\mathrm{D} / \mathrm{H}$ blend sample with the $\mathrm{H}$ molar fraction $\mathrm{X}$ may be given as follows, where the relation $\Delta H-T_{\mathrm{m}} \Delta S=0$ is used.

$$
\begin{aligned}
& T_{\mathrm{m}}= \\
& \frac{\left[X^{2} \Delta H_{\mathrm{hh}}+(1-X)^{2} \Delta H_{\mathrm{dd}}+2 X(1-X) \Delta H_{\mathrm{hd}}\right]}{\left[X^{2} \Delta H_{\mathrm{hh}} / T_{\mathrm{mhh}}^{\mathrm{o}}+(1-X)^{2} \Delta H_{\mathrm{dd}} / T_{\mathrm{mdd}}^{\mathrm{o}}+2 X(1-X) \Delta S_{\mathrm{hd}}\right]}
\end{aligned}
$$

We use the coefficients $k_{\mathrm{hh} / \mathrm{dd}}$ and $k_{\mathrm{hd} / \mathrm{dd}}$ for the ratios of $\Delta H_{\mathrm{hh}} / \Delta H_{\mathrm{dd}}$ and $\Delta H_{\mathrm{hd}} / \Delta H_{\mathrm{dd}}$, respectively. Then eq 3 can be rewritten as

$$
\begin{aligned}
& T_{\mathrm{m}}= \\
& \frac{\left[X^{2} k_{\mathrm{hh} / \mathrm{dd}}+(1-X)^{2}+2 X(1-X) k_{\mathrm{hd} / \mathrm{dd}}\right]}{\left[X^{2} k_{\mathrm{hh} / \mathrm{dd}} / T_{\mathrm{mhh}}^{\mathrm{o}}+(1-X)^{2} / T_{\mathrm{mdd}}^{\mathrm{o}}+2 X(1-X)\left(\Delta S_{\mathrm{hd}} / \Delta H_{\mathrm{dd}}\right)\right]}
\end{aligned}
$$

By selecting the proper numerical values for the parameters $k_{\mathrm{hh} / \mathrm{dd}}, k_{\mathrm{hd} / \mathrm{dd}}$, and $\Delta S_{\mathrm{hd}} / \Delta H_{\mathrm{dd}}$, we can fit the calculated $\mathrm{mp}$ curves to the observed data.

n-Alkane Blends. We may reasonably assume that the $\mathrm{D}$ and $\mathrm{H}$ species of $n$-alkane with the same chain length behave almost equivalently, ${ }^{52}$ although, strictly speaking, the slight difference may be existent for the various 
physical properties. The actual measurement of $\Delta H$ revealed that within the experimental error the relation $\Delta H_{\mathrm{hh}}=\Delta H_{\mathrm{dd}}$ or $k_{\mathrm{hh} / \mathrm{dd}}=1$ may be assumed reasonably. The melting points of the pure components were quoted from the experimental data; $T_{\mathrm{mhh}}^{\mathrm{o}}=64.8^{\circ} \mathrm{C}$ and $T_{\mathrm{mdd}}^{\mathrm{o}}=$ $60.5 \mathrm{C}$. Then the two parameters $k_{\mathrm{hd} / \mathrm{dd}}$ and $\left(\Delta S_{\mathrm{hd}} / \Delta H_{\mathrm{dd}}\right)$ are remained as the adjustable parameters. The solid curve in Figure 1(a) is the thus obtained result, where the parameters were determined as $k_{\mathrm{hd} / \mathrm{dd}}=1.0$ and $\Delta S_{\mathrm{hd}} / \Delta H_{\mathrm{dd}}=0.0030 \mathrm{~K}^{-1}$. The value $k_{\mathrm{hd} / \mathrm{dd}}=1.0$ is reasonable judging from the equivalence between the $\mathrm{D}$ and $\mathrm{H}$ chains, i.e., $k_{\mathrm{hh} / \mathrm{dd}}=1.0$. In this way the melting point data observed for $n$-alkane blends could be reproduced almost perfectly by eq 4 or on a basis of the idea of random distribution of the $\mathrm{H}$ and $\mathrm{D}$ species in the crystal lattice as well as in the melt.

$P E$ Blends. In this case, we may use also the abovementioned eq 4 . The available experimental values are $k_{\mathrm{hh} / \mathrm{dd}}=0.99 . T_{\mathrm{mhh}}^{\mathrm{o}}=102.0^{\circ} \mathrm{C}$ and $T_{\mathrm{mdd}}^{\mathrm{o}}=116.0^{\circ} \mathrm{C}^{36-41} \mathrm{In}$ the calculation of $k_{\mathrm{hh} / \mathrm{dd}}$, the $\Delta H_{\mathrm{hh}}$ and $\Delta H_{\mathrm{dd}}$, the melting enthalpies for the pure crystalline states, were evaluated by correcting the observed enthalpies for the degree of crystallinity $x$, that is, $\Delta H_{\mathrm{dd}}=\Delta H_{\mathrm{dd}(\text { observed })} / x$ where $x$ was estimated by $\mathrm{X}$-ray diffraction method. The result was $\Delta H_{\mathrm{hh}}=126.9 / 0.502=252.8 \mathrm{~J} \mathrm{~g}^{-1}$ and $\Delta H_{\mathrm{dd}}=$ $173.4 / 0.682=254.3 \mathrm{~J} \mathrm{~g}^{-1}$ (refer to in Table II in ref 36), from which $k_{\mathrm{hh} / \mathrm{dd}}=0.99$ was obtained as mentioned above. By adjusting the parameters $k_{\mathrm{hd} / \mathrm{dd}}=1.18$ and $\Delta S_{\mathrm{hd}} / \Delta H_{\mathrm{dd}}=0.003 \mathrm{~K}^{-1}$, we can reproduce the observed melting point data of $\mathrm{PE}$ blends as indicated by a solid line in Figure 1(b). In this case the relation found for $n$-alkane blends $\left(k_{\mathrm{hd} / \mathrm{dd}}=1.0\right)$ is broken. This may come from the slight mismatch in the structure between the two kinds of PE species with (LLDPE) and without (DHDPE) branchings, different from the case of $n$-alkane chains without branching. Anyhow, however, the thermal behaviors of PE blends can be interpreted also reasonably by assuming the perfectly cocrystallized structure between the $H$ and $D$ species, just like the case of $n$-alkane blends.

\section{(B) Infrared Spectra of PE and Alkane Blends}

Not only the above-mentioned DSC data, but also the vibrational spectra support reasonably the cocrystallization of the $\mathrm{D}$ and $\mathrm{H}$ chains in the blends of PE and $n$-alkane. As for the infrared spectra, we already reported the spectral change observed for a series of PE blend samples with different $\mathrm{D} / \mathrm{H}$ content. ${ }^{36-42}$ In the present study we measured again the FT-IR spectra of DHDPE/LLDPE blends at room temperature as shown in Figure 2. Figure 3 shows the case of the n-alkane blends. The spectral behavior of these two kinds of sample is essentially the same. The band splittings of the $\mathrm{CH}_{2}$ (and $\mathrm{CD}_{2}$ ) rocking and scissoring modes change with the $\mathrm{D} / \mathrm{H}$ content. ${ }^{27.28}$ The $\mathrm{CH}_{2}$ bands become almost singlet for the sample with lower $\mathrm{H}$ content, where the splittings of the $\mathrm{CD}_{2}$ bands are significant. The inverse observation is made for the case of lower $\mathrm{D}$ content: the $\mathrm{CD}_{2}$ bands show the singlet character and the $\mathrm{CH}_{2}$ bands show appreciably large splittings. The band splitting occurs due to the vibrational phase correlation between the two chains in the unit cell. As shown in Figures 4(a) and (b). if the $\mathrm{H}$ (or D) chain is surrounded by the D (or $\mathrm{H}$ ) chains in the lattice, the vibrational coupling
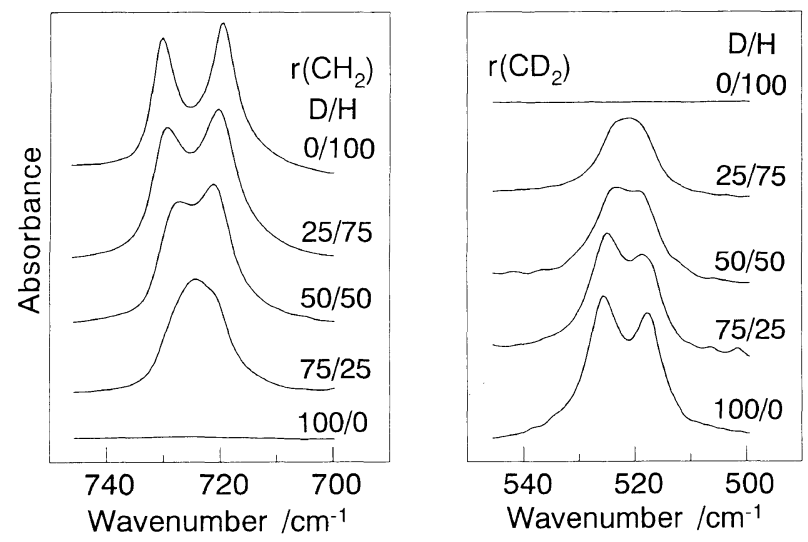

Figure 2. Infrared spectra taken at room temperature for a series of the blend samples between DHDPE and LLDPE with different $\mathrm{D} / \mathrm{H}$ contents.
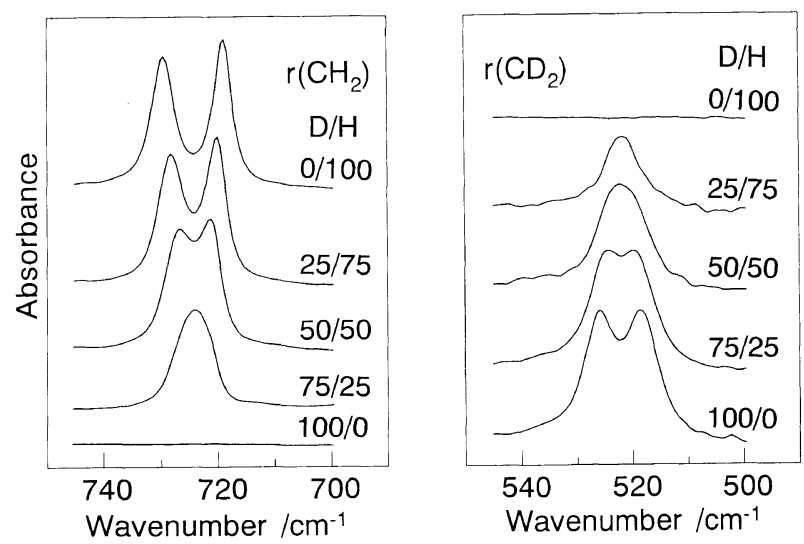

Figure 3. Infrared spectra taken at room temperature for a series of the blend samples between $n-\mathrm{C}_{30} \mathrm{H}_{62}$ and $n-\mathrm{C}_{30} \mathrm{D}_{62}$ with different $\mathrm{D} / \mathrm{H}$ contents. (a)

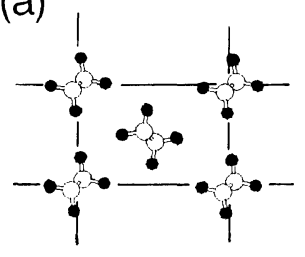

(b)

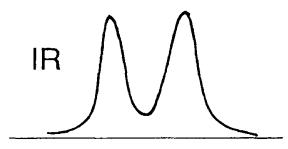

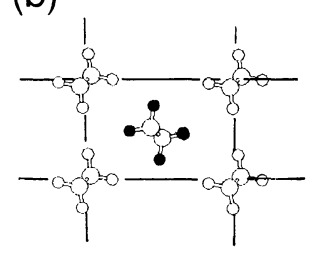

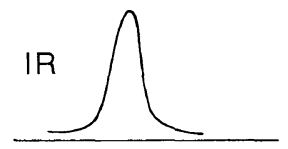

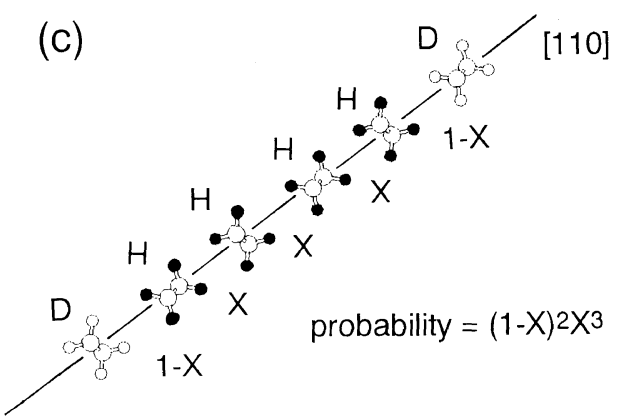

Figure 4. Chain packing modes of orthorhombic polyethylene crystal. (a) All the chains are of the same species, (b) an $\mathrm{H}$ chain is surrounded by $D$ chains, and (c) an illustration of the distribution of the $\mathrm{H}$ and $\mathrm{D}$ chains along the 110 direction. 
(a)

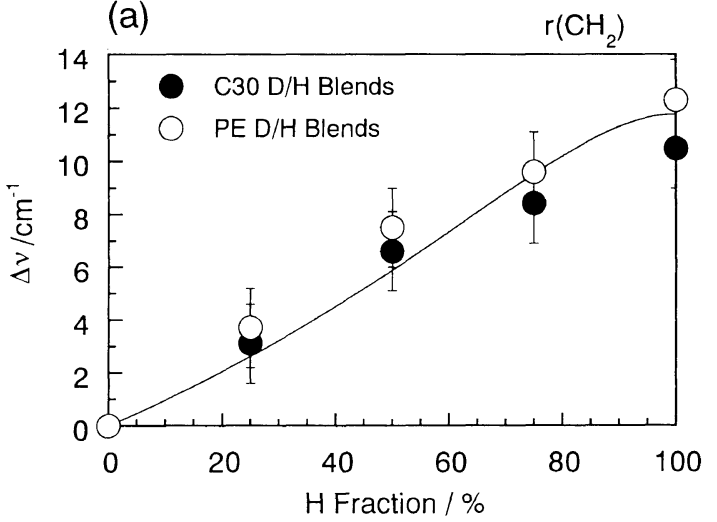

(b)

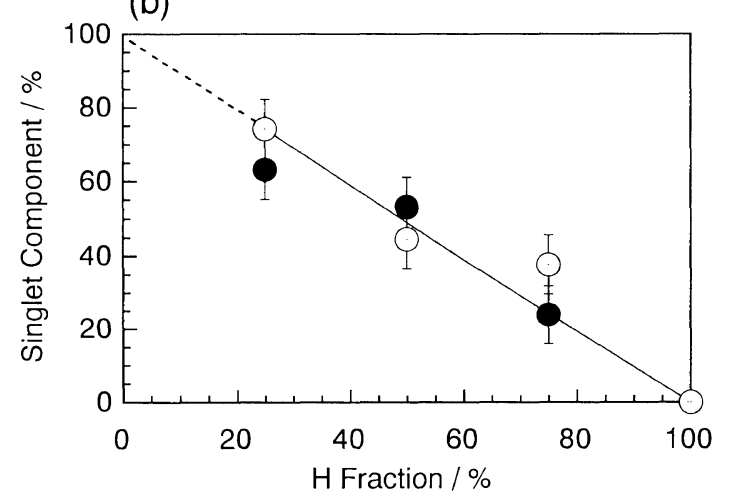

Figure 5. Dependencies of (a) the splitting width and (b) the singlet fraction of the $\mathrm{CH}_{2}$ rocking mode bands on the $\mathrm{H}$ species fraction in the blends of (O) DHDPE and LLDPE and $(O) n-\mathrm{C}_{30} \mathrm{H}_{62}$ and $n-C_{30} \mathrm{D}_{62}$. The solid lines indicate the theoretical curves calculated under the assumption of random distribution of the $D$ and $H$ species in the crystal lattice (see the text).

between the chains of the same species is cut and the band splitting disappears, i.e., the singlet is observed. By increasing the number of surrounding chains of the same kind species with this isolated chain, the vibrational correlation is stronger and the bands show larger splitting.

In Figures 5(a) and (b) are shown, respectively, the band splitting width and the fraction of the singlet component, which were evaluated from Figure 2 for both the $n$-alkane and PE blends. In these analyses the curve separation was carried out for the band profiles shown in Figures 2 and 3. Since the spatial distribution of the $\mathrm{H}$ and $\mathrm{D}$ species is assumed random, the various types of the arrangement are possible for the $\mathrm{H}$ or $\mathrm{D}$ chain clusters, resulting in the various types of the band splitting width. Therefore we have to consider that the observed band profile is contributed by the singlet component, the amorphous bands, and the combination of the band pairs with the various splitting widths. ${ }^{31,42}$ But this treatment is considered to be quite complicated and may give an unlimited number of answers in the curve separation procedure. Then we approximate that the spectral profile is consisted of the three kinds of component; a pair of splitted bands, a singlet and amorphous bands. The amorphous bands were subtracted from the original profile by using the spectra of the molten sample as the first approximation. ${ }^{36}$ The thus obtained "crystalline spectra" were separated into the three bands; a pair of the splitted bands and a singlet. A pair of the splitted band may be assumed as an average of the various kinds of pairs with different splitting widths. The curve separation was made by using a software GRAMS (Galactic Industries Corporation, U.S.A.). In Figure 5, the splitting width of the $\mathrm{CH}_{2}$ rocking band, for example, decreases almost linearly with a decrement of the $\mathrm{H}$ content and at the same time the fraction of the singlet component increases also linearly. It should be emphasized here again that the change in the infrared spectra of the present PE blends is almost perfectly identical to that of the $n$-alkane blends.

The results shown in Figure 5 can be interpreted reasonably by assuming a random mixing of the $\mathrm{H}$ and $\mathrm{D}$ chain stems in the crystalline lattice. In order to simplify the situation, we will treat the equations for the one-dimensional lattice. That is to say, the $\mathrm{H}$ and $\mathrm{D}$ chain stems are assumed to be arrayed along one direction, which is the 110 direction in the case of orthorhombic PE crystal. If two stems of the same type $(\mathrm{H}-\mathrm{H}$ or $\mathrm{D}-\mathrm{D})$ are positioned side by side as shown in Figure 4(c), this pair should give the band splitting. This splitting width of the $\mathrm{CH}_{2}$ band is dependent on the size of the clusters consisting of the same type of chain stems. According to the simple coupled oscillator model, the splitting width of the $\mathrm{CH}_{2}$ bands is given as follows. ${ }^{53.54}$

$$
\Delta v=\Delta v_{0} \cos [\pi /(N+1)]
$$

where $\Delta_{\mathrm{l}}$ is the splitting width expected for onedimensional cluster consisting of the $N$ chain stems and $\Delta v_{\mathrm{o}}$ is that for the infinitely large cluster. Let us assume now that the distribution of the $\mathrm{H}$ and $\mathrm{D}$ chain stems is not influenced by the states of the neighboring chains. Then the probability $f(p)$ to find a sequence of the chain-stem arrangement such as $\cdots \mathrm{D}(\mathrm{H})_{\mathrm{p}} \mathrm{D} \cdots$ is expressed by

$$
f(p)=(1-X)^{2} X^{p-1}
$$

where $X$ is the fraction of the $\mathrm{H}$ stems and the probabilities of the pairs $\mathrm{D} \cdots \mathrm{H}(\mathrm{H} \cdots \mathrm{D})$ and $\mathrm{H} \cdots \mathrm{H}$ are given as $1-X$ and $X$, respectively. Then the averaged size $\langle\mathrm{N}\rangle$ of cluster of the $\mathrm{H}$ stems is calculated as below.

$$
\langle\mathrm{N}\rangle=\sum_{p=1}^{\infty} p f(p) / \sum_{p=1}^{\infty} f(p)=1 /(1-X)
$$

By substituting $\langle\mathrm{N}\rangle$ of eq 7 into $\mathrm{N}$ of eq 5 , we have the following equation.

$$
\Delta v=\Delta v_{0} \cos [\pi(1-X) /(2-X)]
$$

In a similar way, an appearance of the singlet band of the $\mathrm{CH}_{2}$ mode is related with the probability to get the sequence of $\cdots \mathrm{D}-\mathrm{H}-\mathrm{D} \cdots$, which is expressed by $(1-X)^{2}$. If the molar extinction coefficients of the band intensity are denoted by $\varepsilon_{\text {singlet }}$ and $\varepsilon_{\text {doublet }}$ for the singlet and the doublet, respectively, the fraction of the singlet in the total intensity of the bands is given as below. In eq $6, p=1$ corresponds to the singlet band and $p \geq 2$ to the doublet. Then we have the following equation.

Singlet Fraction $=($ singlet $) /($ singlet + doublet $)$

$$
\begin{aligned}
& =\varepsilon_{\text {singlet }}(1-X)^{2} /\left[\varepsilon_{\text {singlet }}(1-X)^{2}+\varepsilon_{\text {doublet }} \sum_{p=2}^{\infty}(1-X)^{2} X^{p-1}\right] \\
& =\varepsilon_{\text {singlet }}(1-X) /\left[\varepsilon_{\text {singlet }}(1-X)+\varepsilon_{\text {doublet }} X\right]
\end{aligned}
$$



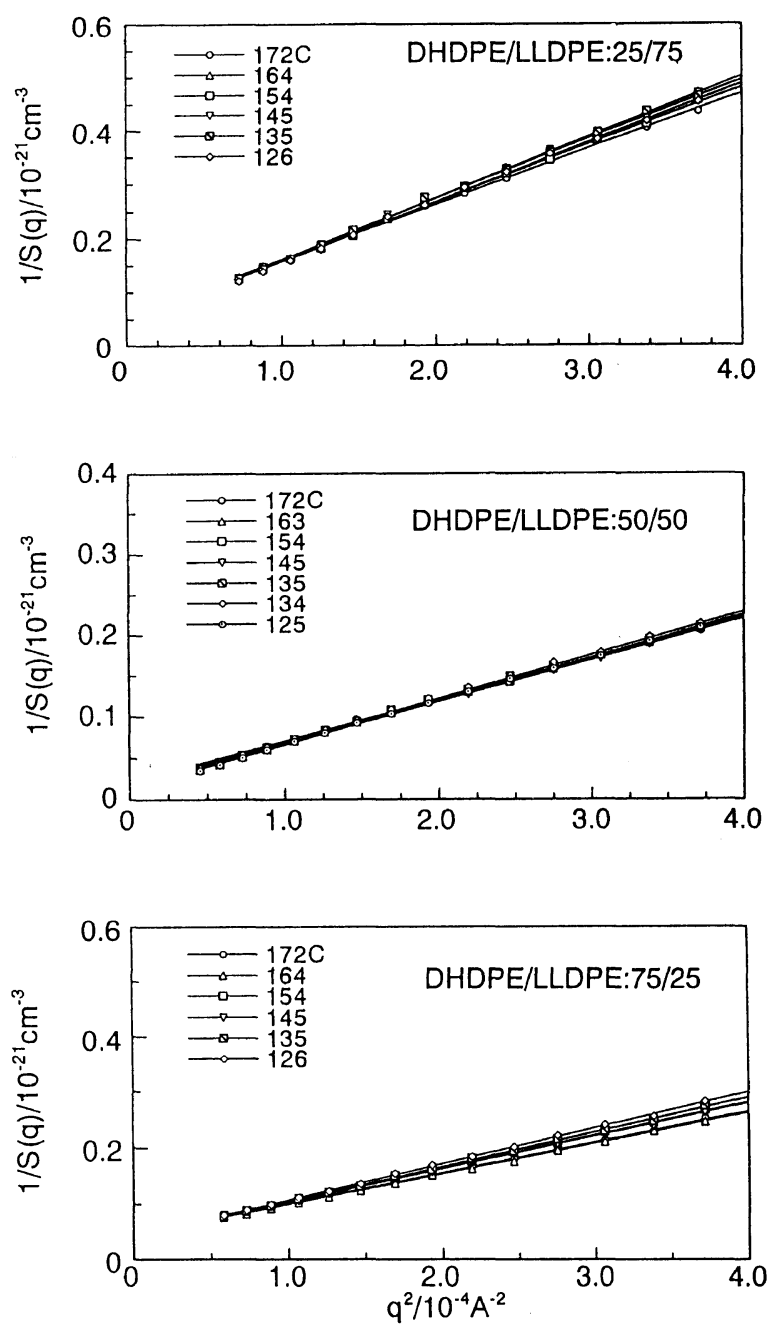

Figure 6. Ornstein-Zernike plots made for the molten states at the various temperatures of the DHDPE/LLDPE blend samples with different $\mathrm{D} / \mathrm{H}$ ratios.

If we assume $\varepsilon_{\text {singlet }}=\varepsilon_{\text {doublet }}$, the singlet fraction can be expressed simply by $1-X$.

The solid lines in Figures 5(a) and (b) indicate, respectively, the calculated results on the basis of eq 8 and 9 , where $\Delta v_{\mathrm{o}}=11.8 \mathrm{~cm}^{-1}$ (observed value for the pure $H$ species) and $\varepsilon_{\text {singlet }}=154.3$ (arbitrary unit) and $\ddot{\varepsilon}_{\text {doublet }}=160.6$ (arbitrary unit) were assumed. The calculated curves can be reproduced well by using eq 8 and 9. In this way the infrared spectral changes observed for a series of PE (and $n$-alkane) blends can be interpreted reasonably by assuming the statistically random distribution of the $\mathrm{D}$ and $\mathrm{H}$ chain stems in the crystal lattice, in other words, by assuming the cocrystallized blend structure.

(C) SANS Data Analysis

As mentioned in the introductory section, the so-far reported SANS studies on the spatial configuration of chains in the melt as well as in the solid state had some difficulty to be accepted because the $\mathrm{D} / \mathrm{H}$ blend samples of high-density PE were used, which show the segregation when cooled slowly from the melt. The samples discussed in the present paper show almost perfect cocrystallization phenomenon even under such a normal condition, allowing us to compare the radius of gyration $\left(R_{\mathrm{g}}\right)$ of a chain in both the states of melt and crystal. The SANS 682

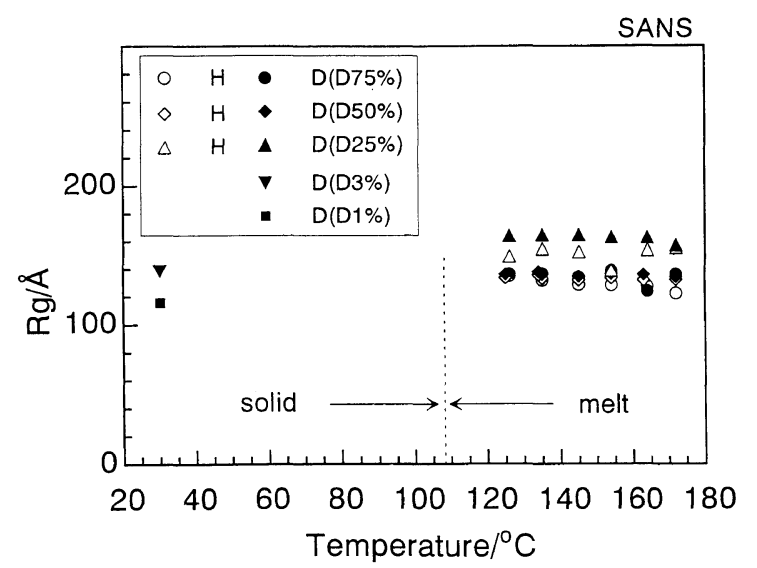

Figure 7. Temperature dependence of the radius of gyration obtained for the $\mathrm{D}$ and $\mathrm{H}$ chains of the DHDPE/LLDPE blend samples with different $\mathrm{D} / \mathrm{H}$ ratios.

data reported in our previous paper ${ }^{44}$ were found to give the overestimation about the temperature dependence of the $R_{\mathrm{g}}$. We doubted the reasonableness of the SANS data themselves as mentioned in the introductory section and then we carefully carried out the SANS measurements again for the present blend samples. The details of the data treatment were already described in the previous paper. ${ }^{44}$

Molten State. The structure factor $S(q)$ at the wave vector $\boldsymbol{q}$ was evaluated from the SANS data and an Ornstein-Zernike plot was made $\left[1 / S(q) v s . \boldsymbol{q}^{2}\right]$ as shown in Figure 6, from which the Flory-Huggins parameter $\chi$ (from the intercept of the straight line) and the radii of gyration $R_{\mathrm{g}}(\mathrm{H})$ and $R_{\mathrm{g}}(\mathrm{D})$ (from the slope) were estimated. ${ }^{44}$ The $R_{\mathrm{g}}(\mathrm{H})$ and $R_{\mathrm{g}}(\mathrm{D})$ are shown in Figure 7 as a function of temperature. They are almost independent of the temperature within the experimental errors; $R_{\mathrm{g}}(\mathrm{H})=130 \AA$ and $R_{\mathrm{g}}(\mathrm{D})=150 \AA$. For the $\mathrm{PE}$ samples with relatively low degree of branching, the relation $R_{\mathrm{g}} / M_{w}{ }^{1 / 2}=0.45 \pm 0.01$ was reported. ${ }^{22.55 .56}$ In the present samples, the values predicted from this relation are $R_{\mathrm{g}}(\mathrm{H})=123 \AA$ and $R_{\mathrm{g}}(\mathrm{D})=147 \AA$, in good agreement with the experimental results in Figure 7. As for the $\chi$ values, they were found to obey such linear relations as $\chi=A+B / T$, where the parameters $A$ and $B$ are listed below.

$\begin{array}{ccc}D \text { fraction } & A & B \\ 25 w \mathrm{t} \% & -3.82 \times 10^{-3} & 1.44 \\ 50 \mathrm{wt} \% & -1.63 \times 10^{-3} & 0.79 \\ 75 \mathrm{wt} \% & -1.44 \times 10^{-3} & 0.43\end{array}$

According to the Flory-Huggins equation, the critical value of $\%$ is written by 56.57

$$
\chi_{\mathrm{c}}=(1 / 2)\left[1 /\left(\phi_{D} N_{w \cdot D}\right)+1 /\left(\phi_{H} N_{w H}\right)\right]
$$

where $\phi_{i}$ and $N_{w i}$ are, respectively, the volume fraction and the weight-average degree of polymerization of the $i$ th component and the volumes of the $\mathrm{D}$ and $\mathrm{H}$ species were assumed to be almost the same in the present case. The calculated $\chi_{\mathrm{c}}$ 's are $7.56 \times 10^{-4}$ (for $D=25 \%$ ), $6.72 \times 10^{-4}$ (for $D=50 \%$ ), and $8.71 \times 10^{-4}$ (for $D=$ $75 \%)$. The $\chi$ values in the whole region of temperature of the melt are about $-5 \times 10^{-4}($ for $D=25 \%), 3 \times 10^{-4}$ (for $D=50 \%)$, and $-5 \times 10^{-4}(D=75 \%)$, which are smaller than $\chi_{c}$, suggesting that these blend systems do 
(a)
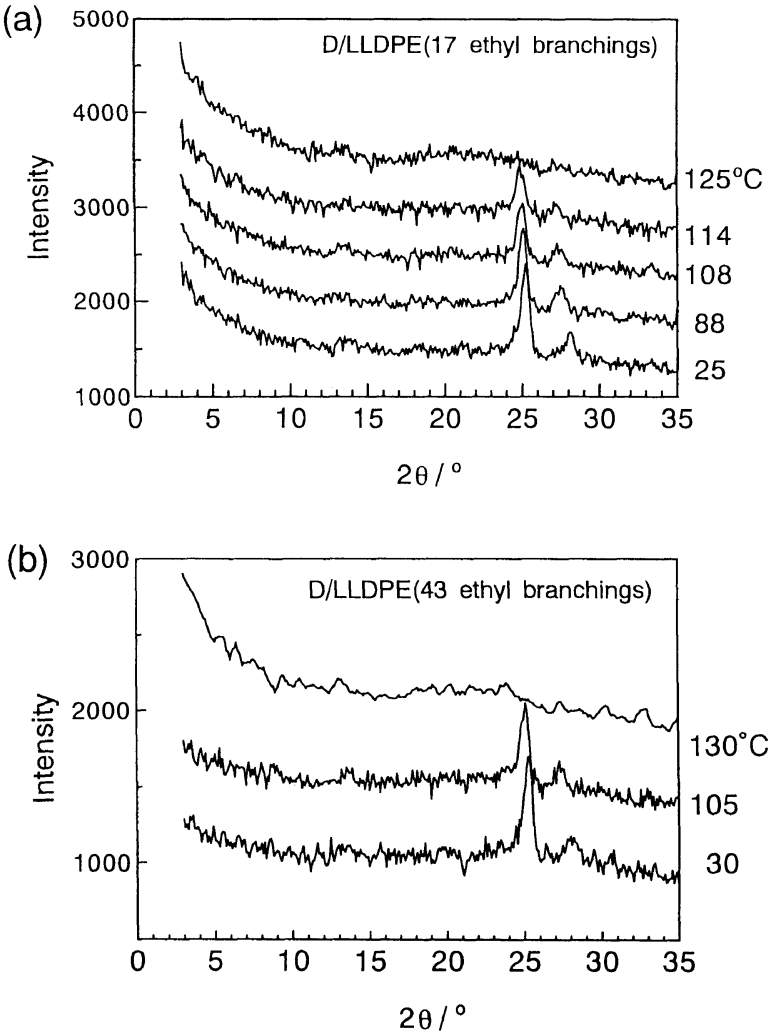

Figure 8. WANS profiles measured at the various temperatures for the DHDPE/LLDPE blend samples. (a) The case of almost perfect cocrystallization in both the melt and the crystalline states, where LLDPE with 17 ethyl branchings/1000C was used, and (b) the case of cocrystallization in the melt but phase segregation at solid state between the $\mathrm{D}$ and $\mathrm{H}$ species, where LLDPE with 43 ethyl branchings/1000C was used.

not show the phase segregation phenomenon in the molten state. ${ }^{26,57-61}$ The $\chi$ changes between positive and negative values depending on the $\mathrm{D} / \mathrm{H}$ content, the reason of which will be a future problem to be solved. Although the aggregation structure of the blends of linear and branched PE in the melt is now being discussed in many papers ${ }^{26.57-61}$ and there may be still some controversy about the point whether these two components are segregated or miscible, the DHDPE and LLDPE components can be experimentally assumed to be homogeneously mixed in the melt as far as the sample used in the present study is concerned.

Room Temperature. The SANS data were obtained also at room temperature for the blend samples with low D concentration ( 1 and $3 \mathrm{wt} \%$ ). The data treatment was made following the method described in the previous paper. ${ }^{44}$ The thus evaluated $R_{\mathrm{g}}$ is plotted in Figure 7 in comparison with those obtained for the molten state. Within the experimental errors, the $R_{\mathrm{g}}$ is almost constant independently of the temperature covering both the melt and the solid state.

This experimental result is important. Many papers reported the similar results for the blend samples between DHDPE and HDPE on the basis of the SANS measurements. But, in these experiments, the samples quenched from the melt were used in order to avoid the phase segregation between the $\mathrm{D}$ and $\mathrm{H}$ species, as already pointed out in the introductory section. The D and $\mathrm{H}$ chains included in the samples used in the present (a)

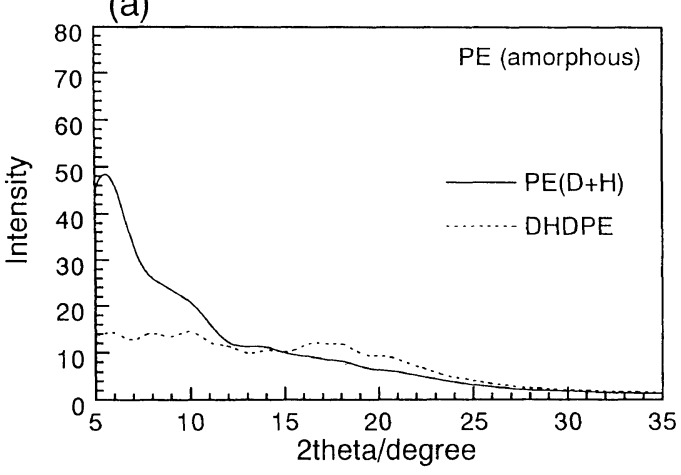

(b)

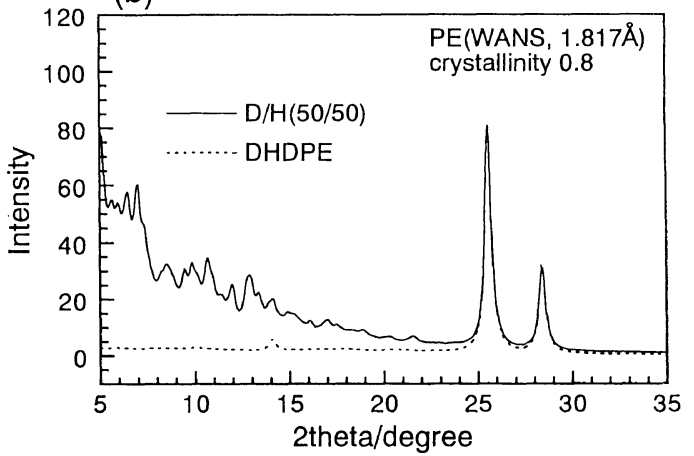

Figure 9. WANS profiles simulated for (a) amorphous state and (b) semi-crystalline state (degree of crystallinity 0.8 assumed) of the PE models. . the blend consisting of the $D$ and $H$ chains at 50:50 ratio:- - the pure $D$ chains (see the text).

study are almost perfectly cocrystallized in the crystalline lamellae even when the samples were cooled slowly from the melt. Therefore we may say as a general tendency of PE that the $R_{\mathrm{g}}$ of a chain is kept unchanged before and after the crystallization from the melt. More detailed discussion will be made in a later section.

\section{(D) WANS Data Analysis}

Figure 8(a) shows the WANS data obtained at the various temperatures for the DHDPE/LLDPE sample with the $\mathrm{H}$ fraction $50 \mathrm{wt} \%$ (cooled process). In Figure 8(b) are shown also the data collected for the PE blend of DHDPE with more highly-branched LLDPE (about 43 ethyl branchings/1000 carbon atoms) at $50 \mathrm{wt} \%$. This blend does not show the cocrystallization phenomenon except for the case of low concentration $(<25 \mathrm{wt} \%)^{36-42}$. In the former case of DHDPE/ LLDPE blend shown in Figure 8(a), the broad scattering is observed in the low scattering angle region not only for the molten state but also for the crystalline state. This scattering is considered to come from the randomly mixed structure of the $\mathrm{D}$ and $\mathrm{H}$ stems. ${ }^{17,18} \mathrm{On}$ the other hand, in the latter case of DHDPE/LLDPE with high branching content, as shown in Figure $8(\mathrm{~b})$, the broad scattering is observed clearly in the molten state but diminishes in the solid state. This is because the phase segregation occurs between the crystalline lamellae of the $\mathrm{D}$ and $\mathrm{H}$ species.

These differences in the broad scattering in the low angle region can be simulated on the basis of the randomly packed model of the $\mathrm{D}$ and $\mathrm{H}$ chains. For example, Figure 9(a) shows the WANS patterns calculated for the amorphous state. One is the model 
(a)

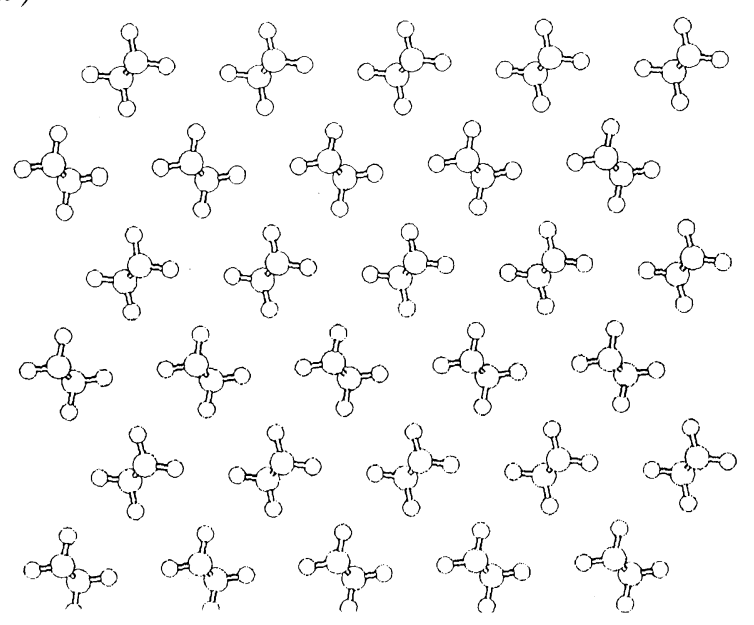

(b)

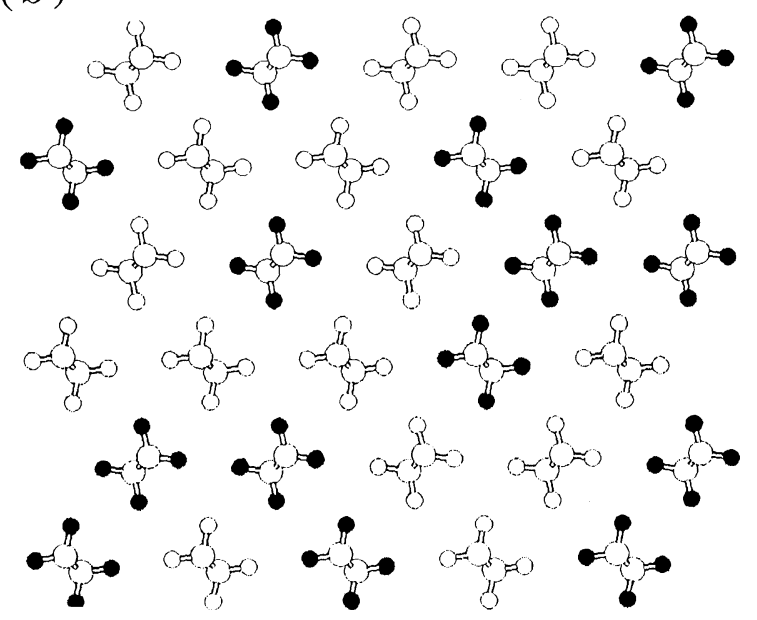

Figure 10. Packing models of the $\mathrm{D}$ and $\mathrm{H}$ chain stems in the crystal lattice of orthorhombic PE. (a) pure D chains and (b) the random packing of the the $\mathrm{D}$ and $\mathrm{H}$ chains at $50: 50$ ratio.

with the randomly mixed $20 \mathrm{D}$ and $20 \mathrm{H}$ chains, each of which consists of $20 \mathrm{CH}_{2}$ units. Another is the model constructed by 40 chains of the $\mathrm{D}$ species alone. The modeling and calculation of WANS pattern were made by using Cerius $^{2}$ (version 3.5, Molecular Simulations Corporation, U.S.A.). Figure 9 (b) shows the simulated WANS patterns for the semicrystalline states with the assumed degree of crystallinity 0.8 . They were the summations of the two types of profiles calculated for the infinitely large crystal lattice consisted of the pure D or the mixed D/H chains (see Figure 10) and for the amorphous state. In both the cases of Figures 9(a) and (b), the broad scatterings are observed clearly for the randomly mixed $\mathrm{D} / \mathrm{H}$ blend structure but not for the pure D sample.

\section{Structural Features of PE Crystallite}

(A) Chain Folding Mode in PE Crystallite

The above-mentioned experimental data collected for the DHDPE/LLDPE blend samples may be summarized in the following ways.

(1) The melting peak of the DSC curve shifts continuously with the $\mathrm{D} / \mathrm{H}$ content. (a)

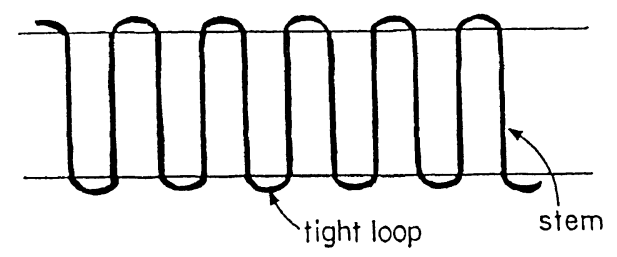

(b)

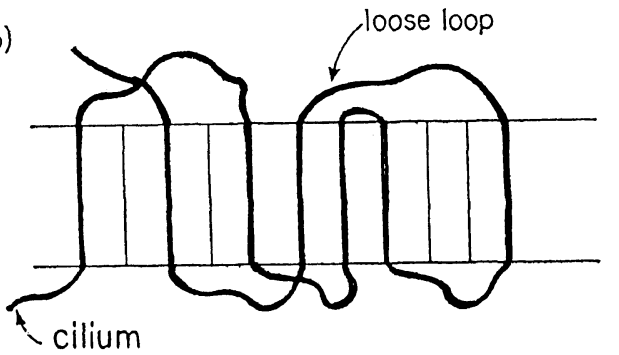

(c)

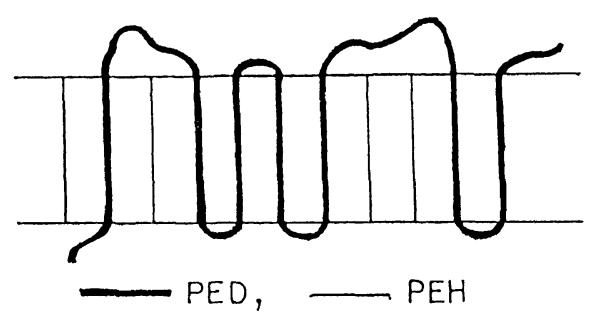

Figure 11. Illustration of the various types of chain folding structure. (a) regular adjacent reentry, (b) random reentry, and (c) cluster model consisting of the mixture of (a) and (b).

(2) The infrared band splittings and the fraction of the singlet band change systematically depending on the $\mathrm{D} / \mathrm{H}$ content.

(3) The homogeneous mixing of the $\mathrm{D}$ and $\mathrm{H}$ chains can be seen in both the molten state and the crystalline state of the $\mathrm{D} / \mathrm{H}$ blend samples.

(4) The radii of gyration $\left(R_{\mathrm{g}}\right)$ of the $\mathrm{D}$ and $\mathrm{H}$ chains do not change before and after crystallization from the melt.

(5) The broad scattering is observed in the low angle region of the WANS pattern for the cocrystallized $\mathrm{D} / \mathrm{H}$ blend sample as well as for the molten state.

It should be also noticed that the behaviors (1) and (2) are commonly observed for both the samples of PE and $n$-alkane. All the experimental results of (1), (2), (3), and (5) have been able to be interpreted reasonably by developing the theoretical equations or by computer simulations on the basis of the structural model in which the $\mathrm{D}$ and $\mathrm{H}$ chains are statistically randomly packed in the crystal lattice, as already described in the previous sections.

What is meant by this structural model of random packing of the $\mathrm{D}$ and $\mathrm{H}$ chains ? The above-mentioned experimental data (1), (2), and (5) are concerned only with the parts of extended chain stems included in the crystalline lattice. But the idea of random arrangement of the chain stems may be reasonably connected with the statement that the PE chains experience the random reentry folding on the surface of the crystalline lamellae, as illustrated in Figure 11(b). ${ }^{9,13}$ The regular adjacent reentry model shown in Figure 11(a) is questionable 
(a) Melt
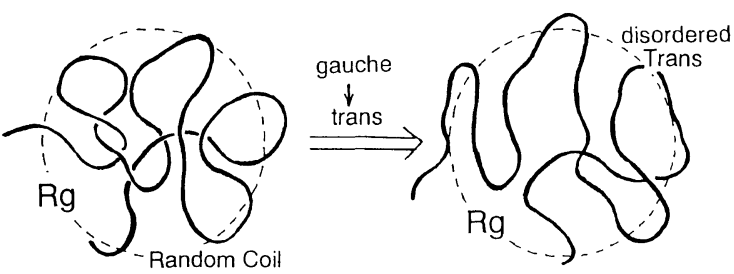

$\downarrow$

(d) Time Region III

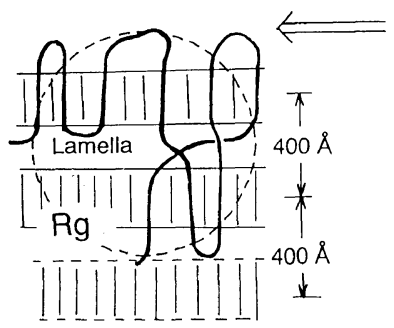

(c) Time Region II

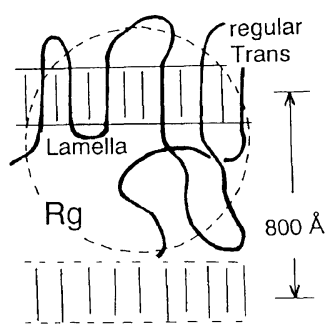

Figure 12. Illustrated structural change in the crystallization process of PE from the melt. The segments of the random coils change to the regular zigzag conformation via the disordered trans form. In this course of disorder-to-order transition of the chains, the formation and stacking of lamellac occur. It should be noted that the radius of gyration of the chain is not changed in this process.

judging from all the experimental data mentioned above. However, it might be difficult at the present stage to affirm that the chain reentry is statistically perfectly random. For example, the model of Figure 11(c), which is a mixture of the adjacent reentry folding parts and the random reentry parts, might be used to interpret the above-mentioned experimental data. ${ }^{14,15}$ More exact and more quantitative investigation must be made in future. Anyway, we may propose quite reasonably and logically that the random reentry is the most realistic chain folding mode, at least, for the PE sample consisting of DHDPE and LLDPE.

\section{(B) Structural Change in Crystallization Process}

We have another important experimental result (4), which states that the radius of gyration of an individual chain is kept unchanged even when the chain is enrolled into the crystalline lamella from the melt. In the previous papers we described the structural change of the PE chains in the crystallization process from the melt on the basis of the experimental data collected by the time-resolved small-angle X-ray scattering and FT-IR measurements. ${ }^{62.63}$ The experimental data allowed us to have the following image of structural change. Immediately after the beginning of the isothermal crystallization, the conformationally-disordered trans form starts to appear from the random coils of the melt and grows in population. After a while, the disordered-trans form changes into the regular trans-zigzag form. In parallel to it, the formation of isolated lamellae is induced and the formation of the lamellar stacking structure with a period of $c a$. $800 \AA$ occurs. With the passage of time, the $800 \AA$ periodical structure changes to the structure with a long period of $c a$. $400 \AA$, indicating that new lamellae are created in between the already existing lamellae and the more densely stacked lamellar structure is constructed.

If we combine these structural information with the constancy of the spatial size $\left(R_{\mathrm{g}}\right)$ of the individual molecular chains before and after the crystallization, then we may draw more concrete model for the structural change of the chains in the course of crystallization, as shown in Figure 12. The molecular chains in the melt take the form of random coils. When the sample is cooled to the crystallization temperature, some parts of the chain segments change their conformation to the disordered trans form, just when the total size of the chain is not changed in average (Time Region I). The chains are entangled with each other but the disordered trans segments of these entangled parts are gathered together to form a single lamella by arranging themselves side by side, just when the molecular chain segments change the conformation to more regular trans-zigzag form (Time Region II). As a result, the chain folding of random reentry type is realized [Figure $11(\mathrm{~b})$ ]. The total size of the chain is not still changed. This model happens to be found to be equivalent to the model proposed by Fischer et al. (Solidification Model), although they proposed it for the melt-quenched sample.

\section{CONCLUSIONS}

In the present report we investigated the aggregation structure of PE chains in the crystalline state as well as in the molten state by organizedly combined experimental data of the small-angle neutron scattering, infrared spectra and thermal analysis. All these data could be interpreted reasonably in terms of the statistically random packing structure of the polymer chains in the crystalline lamella. This conclusion led us necessarily to the description of random reentry type for the chain folding mode of PE. This idea is just identical to the switch-board model proposed by Flory, ${ }^{13}$ Fischer, ${ }^{16}$ and so on. But it should be noticed that the sample used in this study is the blends between the $D$ and $H$ species which can cocrystallize almost perfectly in the common crystalline lattice even when the samples are cooled quite slowly from the melt. This is quite different from the cases utilized by the previous researchers: they used the melt-quenched samples to avoid the phase separation between the $\mathrm{D}$ and $\mathrm{H}$ species.

We said that the samples used in the present experiments were crystallized from the melt at cooling rate as slow as possible. We do not know, however, what happens when the crystallization rate is reduced to much higher degree (for example, in a time scale of months or years). If the rate of the diffusion and reptation motion of the entangled chains is faster than the crystallization rate or the rate of parallel arrangement of stems, the chains may be able to escape from the entanglement and form the structure of regular adjacent reentry. In order to check this possibility, we are now trying to study the aggregation structure of chains in the crystalline state which should be obtained under the condition of much smaller degree of supercooling, although the temperature control will be tremendously difficult. Any way, at least, the $\Delta T$ of $0.1-1^{\circ} \mathrm{C}$ gave us the conclusion of almost perfect cocrystallization phenomenon for the present DHDPE/LLDPE blend sample. 
We need to have another question. In the present paper we used the D/H blends of DHDPE and hydrogeneous LLDPE with small amount of ethyl branching. At least, this pair of $D$ and $H$ polymers cocrystallizes almost perfectly and gives us the ideas of the random packing of the chain stems in the lamella and the random reentry folding. But is it really possible to transfer these ideas to the case of pure HDPE itself? We assumed and have confirmed actually that the LLDPE used in this experiment shows the crystallization behavior, structural feature, etc. similar to those of HDPE. But, even if it may be so, we will have to check the aggregation structure of chains and the folding structure of pure HDPE sample by any possible method. At the present stage, we believe the methods and principles employed in this paper are not very much unreasonable and the structure features deduced from the thus obtained data for the $\mathrm{D} / \mathrm{H}$ blend samples might be accepted as the general characters of $\mathrm{PE}$ itself, which is crystallized under the normal crystallization conditions.

\section{REFERENCES AND NOTES}

1. Special issue on chain folding problem; Faraday Discuss. Chem. Soc., 68, 1979

2. Proceedings of the NATO Advanced Research Workshop on Crystallization of Polymers, M. Dasiere, Ed., Series C, No. 405. Kluwer Academic Publishers, 1993.

3. F. C. Stehling. E. Engos, and L. Mandelken, Macromolecules, 4. 672 (1971).

4. J. S. Schelten, G. D. Wignall, D. G. H. Ballard, and W. Schmatz, Coll. Polym. Sci., 252, 749 (1974).

5. J. Shelten, G. D. Wignall, and D. G. H. Ballard, Polymer, 15, 682 (1974).

6. J. Schelten, D. G. H. Ballard, G. D. Wignall, G. Longman, and W. Schmatz, Polvmer, 17, 751 (1976).

7. J. Schelten, G. D. Wignall, D. G. H. Ballard, and G. W. Longman, Polymer, 18, 1111 (1977).

8. D. M. Sadler and A. Keller, Macromolecules, 10, 1128 (1977).

9. D. Y. Yoon and P. J. Flory, Polvmer, 18. 509 (1977).

10. A. Maconnachie and R.W. Richards, Polymer, 19, 739 (1978).

11. D. M. Sadler and A. Keller, Makromol. Sci., 203, 263 (1979).

12. M. Stamm, E. W. Fisher, M. Dettenmaier, and P. Convert, Faraday Discuss. Chem. Soc., 68, 263 (1979).

13. D. Y. Yoon and P. J. Flory, Faraday Discuss. Chem. Soc., 68 , 288 (1979).

14. J. D. Hoffman, C. M. Guttman, and E. A. Dimanzio, Faraday Discuss. Chem. Soc., 68, 77 (1979).

15. C. M. Guttman, J. D. Hoffman, and E. A. DiMarzio, Faraday Discuss. Chem. Soc., 68, 297 (1979).

16. M. Dettenmaier, E. W. Fischer, and M. Stamm, Coll. Polym. Sci., 258, 343 (1980)

17. G. D. Wignall, L. Mandelkern, C. Edwards, and M. Glotin, J. Polym. Sci., Phys. Ed., 20, 245 (1982).

18. M. Stamm, J. Polym. Sci. Phys. Ed., 20, 235 (1982).

19. S. J. Spells, D. M. Sadler, and A. Keller. Polymer, 21, 1121 (1980).

20. S. J. Spells and D. M. Sadler, Polymer, 25. 739 (1984).

21. E. W. Fischer, K. Hahn, J. Kugler, U. Struth, R. Born, and M. Stamm, J. Polym. Sci., Polym. Phys. Ed., 22, 1491 (1984).

22. G. D. Wignall, "Encyclopedia of Polymer Science and Engineering," Vol. 10, M. Grayson and E. M. Kroschwitz, Ed., Wiley and Sons, New York, N.Y., 1987, p 112.

23. J. D. Londono, A. H. Narten, G. D. Wignall, K. G. Honnell, E. T. Hsieh, T. W. Johnson, and F. S. Bates, Macromolecules, 27, 2864 (1994)

24. R. G. Alamo, J. D. London, L. Mandelkern, F. C. Stehling, and
G. D. Wignall, Macromolecules, 27, 411 (1994).

25. G. D. Wignall, J. D. Londono, J. S. Lin, R. G. Alamo, M. J. Galante, and L. Mandelkern, Macromolecules, 28, 3156 (1995).

26. R. G. Alamo, W. W. Graessley, R. Krishnamoorti, D. J. Lohse, J. D. Londono, L. Mandelkern, F. C. Stehling, and G. D. Wignall, Macromolecules, 30, 561 (1997).

27. M. Tasumi and S. Krimm J. Chem. Phys., 46, 755 (1967).

28. M. Tasumi and S. Krimm, J. Polym. Sci., Part A 2, 6, 995 (1968).

29. M. I. Bank and S. Krimm. J. Polvm. Sci., Polym. Phys. Ed., 7, 1785 (1969).

30. M. I. Bank and S. Krimm, J. Polym. Sci., Polym. Lett. Ed., 8, $143(1970)$.

31. T. C. Cheam and S. Krimm, J. Polym. Sci., Polym. Phys. Ed., 19, 423 (1981)

32. X. Jing and S. Krimm, J. Polym. Sci., Polym.Phys. Ed., 20, 1155 (1982)

33. S. Krimm and J. H. Ching, Macromolecules, 5, 209 (1972).

34. B. Wunderlich, G. D. Wignall, D. G. H. Ballard, and W. Shmatz, Coll. Polvm. Sci., 252, 749 (1974).

35. A. Keller, Faraday Discuss. Chem. Soc., 68, 143 (1979).

36. K. Tashiro, R. S. Stein, and S. L. Hsu, Macromolecules, 25, 1801 (1992).

37. K. Tashiro, M. M. Satkowski, R. S. Stein, Y. Li, B. Chu, and S. L. Hsu, Macromolecules, 25, 1809 (1992).

38. K. Tashiro, M. Ituchi, M. Kobayashi, and R. S. Stein, Macromolecules, 27, 1221 (1994).

39. K. Tashiro, M. Izuchi, M. Kobayashi, and R. S. Stein. Macromolecules, 27, 1228 (1994).

40. K. Tashiro, M. Izuchi, M. Kobayashi, and R. S. Stein, Macromolecules, 27, 1234 (1994).

41. K. Tashiro, M. Izuchi, F. Kaneuchi, C. Jin, M. Kobayashi, and R. S. Stein, Macromolecules, 27, 1240 (1994).

42. K. Tashiro, Acta Polvmer. 46, 100 (1995).

43. K. Tashiro, K. Imanishi, Y. Izumi, M. Kobayashi, K. Kobayashi, M. Satoh, and R. S. Stein, Macromolecules, 28, 8477 (1995).

44. K. Tashiro, K. Imanishi, M. Izuchi, M. Kobayashi, Y. Itoh, M. Imai, Y. Yamaguchi, M. Ohashi, and R. S. Stein, Macromolecules, 28, 8484 (1995)

45. D. R. Norton and A. Keller, J. Mater. Sci., 19, 447 (1984).

46. S.-R. Hu, T. Kyu, and R. S. Stein, J. Polym. Sci., Polym. Phys. Ed., 25, 71 (1987).

47. J. M. Rego Lopez and U. W. Gedde, Polvmer, 30, 22 (1989).

48. M. T. Conde Brana and U. W. Gedde, Polymer, 33, 3123 (1992).

49. R. G. Alamo, B. D. Viers, and L. Mandelkern, Macromolecules, 26, 5740 (1993)

50. A. D. English, P. Smith and D. E. Axelson, Polymer, 26, 1523 (1985).

51. P. G. de Gennes, "Scaling Concepts in Polymer Physics," Cornell University Press, Ithaca, N.Y., 1979.

52. D. L. Dorset, Macromolecules, 24, 6521 (1991).

53. R. G. Snyder, M. C. Goh, Svivatsavoy, H. L. Strauss, and D. L. Dorset, J. Phys. Chem., 96, 10008 (1992).

54. R. Zbinden, "Infrared Spectroscopy of High Polymers," Academic Press, New York, N.Y., 1964.

55. G. Lieser, E. W. Fischer, and K. Ibel, J. Polym. Sci., Polym. Lett. Ed., 28, 39 (1975).

56. A. T. Boothroyd, A. R. Rennie, and C. B. Boothroyd, Europhys. Lett., 15, 715 (1991).

57. M. J. Hill, P. J. Barham, A. Keller, and C. C. A. Rosney, Polymer, 32, 1384 (1991)

58. M. J. Hill, P. J. Barham, and A. Keller, Polymer, 33, 2530 (1992).

59. M. J. Hill and P. J. Barham, Polymer, 33, 4099 (1992).

60. C. C. Puig, J. A. Odell, M. J. Hill, P. J. Barham, and M. J. Folkes, Polymer, 35, 2452 (1994).

61. C. Schipp, M. J. Hill, P. J. Barham, V. M. Cloke, J. S. Higgins, and L. Oiarzabal, Polymer, 37, 2291 (1996).

62. K. Tashiro, S. Sasaki, and M. Kobayashi, Polym. J., 30, 485 (1998).

63. K. Tashiro, S. Sasaki, M. Kobayashi, Y. Izumi, and K. Kobayashi. Polymer, in press. 